\title{
Addressing Avoidable Vision Impairment in Mozambique and the Africa Region
}

\author{
Stephen Thompson \\ Technological University Dublin, Ireland \\ Kovin Naidoo \\ African Vision Research Institute \\ Joel Bambamba \\ Universidade Lúrio Faculdade de Ciências de Saúde: Nampula, Nampula, Mozambique
}

See next page for additional authors

Follow this and additional works at: https://arrow.tudublin.ie/scschphyart

Part of the Optometry Commons, and the Place and Environment Commons

\section{Recommended Citation}

Thompson, S., Naidoo, K. \& Bambamba, J. (2018). Addressing Avoidable Vision Impairment in Mozambique and the Africa Region. Development in Practice, https://doi.org/10.1080/ 09614524.2018.1521786 doi.org/10.1080/09614524.2018.1521786

This Article is brought to you for free and open access by the School of Physics \& Clinical \& Optometric Science at ARROW@TU Dublin. It has been accepted for inclusion in Articles by an authorized administrator of ARROW@TU Dublin. For more information, please contact arrow.admin@tudublin.ie, aisling.coyne@tudublin.ie, gerard.connolly@tudublin.ie.

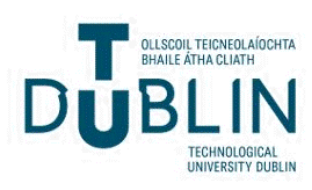




\section{Authors}

Stephen Thompson, Kovin Naidoo, Joel Bambamba, Vanessa R. Moodley, Diane Van Staden, Amanda Forde, Kajal Shah, Luigi Bilotto, and James Loughman 


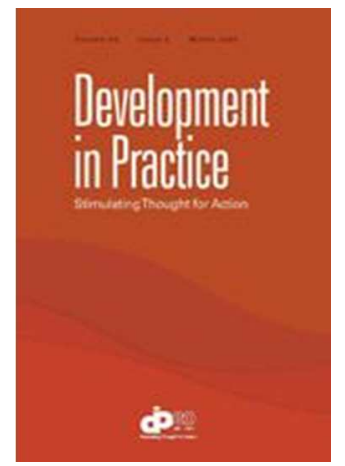

\section{Addressing avoidable vision impairment through sustainable human resource development}

\begin{tabular}{|r|l|}
\hline Journal: & Development in Practice \\
\hline Manuscript ID & Draft \\
\hline Manuscript Type: & Practical Note \\
\hline Keywords: & $\begin{array}{l}\text { Partnership < Civil society, Disability < Gender and diversity, Poverty } \\
\text { reduction < Labour and livelihoods, Economics < Labour and livelihoods, } \\
\text { Education < Social sector, Health < Social sector, Region: Sub-Saharan } \\
\text { Africa, Capacity development < Aid }\end{array}$ \\
\hline Abstract: & $\begin{array}{l}\text { The Mozambique Eyecare Project was an international partnership that } \\
\text { developed a sustainable model for eye health education. An optometry } \\
\text { degree was implemented at Universidade Lúrio, Mozambique. The } \\
\text { optometry graduates were subsequently integrated into the national health } \\
\text { system. In addition, existing eye health workers were upskilled with } \\
\text { training. Researchers from various disciplines evaluated the project and its } \\
\text { potential for impact on eye health in the region. The body of evidence } \\
\text { generated from the research provides useful lessons for development } \\
\text { programmes in general, as well as specific lessons for delivering } \\
\text { sustainable eye health education and service delivery models for low } \\
\text { income settings. }\end{array}$ \\
\hline
\end{tabular}




\title{
Addressing avoidable vision impairment through sustainable human resource development
}

\begin{abstract}
The Mozambique Eyecare Project was an international partnership that developed a sustainable model for eye health education. An optometry degree was implemented at Universidade Lúrio, Mozambique. The optometry graduates were subsequently integrated into the national health system. In addition, existing eye health workers were upskilled with training. Researchers from various disciplines evaluated the project and its potential for impact on eye health in the region. The body of evidence generated from the research provides useful lessons for development programmes in general, as well as specific lessons for delivering sustainable eye health education and service delivery models for low income settings.
\end{abstract}

\section{Key words}

Capacity development, Partnership, Disability, Poverty reduction, Economics, Education, Health, SubSaharan Africa 


\section{Introduction}

There are an estimated 253 million people living with vision impairment (VI) in the world. Over $80 \%$ of all VI can be prevented or cured. Globally, uncorrected refractive error (URE), a disorder where the eye cannot focus correctly, is the main cause of $\mathrm{VI}$ (WHO 2017). The prevalence of $\mathrm{VI}$ in Mozambique was found to be $3.5 \%$ (95\%, Cl 2.7\%-4.2\%). URE prevalence in Mozambique was found to be $2.6 \%$ (95\%, $\mathrm{Cl} 2.1-3.2 \%)$, and was established as the primary cause of $\mathrm{VI}$ among $64.5 \%$ of cases. Despite the fact that most cases of refractive error (RE) can be addressed with spectacles dispensed after an eye test, spectacle coverage in Mozambique was found to be $0 \%$. The prevalence of Presbyopia (a form of RE that occurs typically in middle and old age) was found to be $25.8 \%(95 \%$, Cl $12.0-30.5 \%)$, with $2.2 \%$ spectacle coverage (Loughman et al. 2015). The number of adequately trained professionals present in Mozambique was found to be insufficient to address the burden of URE (Moodley, Loughman, and Naidoo 2014). The spectacle supply system was also reported as inadequate. The demand for eye health services and a dearth of appropriate human resources (HR) in Mozambique and other countries in the Africa region have motivated the establishment of optometry training programmes (Moodley, Loughman, and Naidoo 2015). High URE prevalence and the low level of spectacle coverage in Mozambique indicated an urgent need for the development and delivery of a comprehensive RE service (Loughman et al. 2015). The Mozambique Eyecare Project (MEP) - a North-South partnership between Dublin Institute of Technology (DIT), University of Ulster (UU), Universidade Lúrio (UniLúrio) and Brien Holden Vision Institute (BHVI) - implemented a sustainable model of optometric education and service delivery in Mozambique, with potential for adaptation to other low income settings.

\section{Methodology and research objective}

Under the MEP, an international team of researchers from various disciplines including vision science, public health and social sciences undertook a series of investigations into higher education for eye health in the Africa region. The findings of these investigations were published as peer reviewed articles. The research objective of this practical note is to synthesise the evidence generated from the resulting portfolio of research. This paper details the lessons learnt from the MEP for the benefit of future eye health education programmes and other development programmes being implemented in low income contexts.

\section{Lessons from the Mozambique Eyecare Project}

As part of the MEP, an optometry undergraduate degree program was implemented at UniLúrio, Mozambique, based on a curriculum developed by BHVI with competencies drawn from the global competency-based model of the World Council of Optometry (WCO) and the Association of Regulatory Boards of Optometry (ARBO) (Shah et al. 2017). Prior to the MEP, there were no appropriately qualified optometrists in Mozambique (Wallace, Loughman, and Naidoo 2016). Aside from functional and health 
benefits, the development of an optometry system was shown to be economically justifiable. A Cost Benefit Analysis indicated that by correcting URE in 24.3 million potentially economically productive persons, a net present value of societal benefit of up to $\$ 1.1$ billion is possible by 2049 . This represents a Benefit-Cost ratio of 14:1 (Thompson et al. 2014). The first optometrists graduated in 2013. Table 1 shows the net present value of societal benefits for the first 10 years of the optometry programme, which was negative until the first optometrists graduated and began to treat URE. From that point forward, the net present value of societal benefit was positive for every year included in the analysis, until 2049. Appropriately trained personnel are now unlocking the potential for improved economic productivity by eliminating avoidable VI (Thompson et al. 2014).

[Table 1]

The establishment of optometry as a new profession was found to present several challenges in terms of integration with the existing national eye health system. Failure to address professional regulatory requirements for new programs (where equal or similar qualifications do not already exist) could result in the profession not being officially recognised by the relevant health authorities, restricting its integration into public health services. Recognition of qualifications and the mainstreaming of service provision are essential to protect the public from unscrupulous health care practices (Wallace, Loughman, and Naidoo 2016).

When developing health programmes, training standards and scope of practice must be appropriate to local needs (Wallace, Loughman, and Naidoo 2016). This can be achieved by ensuring that educational quality assurance standards are prioritised, and by underpinning the optometric education programme in principles of social accountability. Socially accountable programmes ensure that local health needs and social determinants inform programme design, governance, curriculum, HR, quality assurance and research. A socially accountable quality assurance framework for optometric education was developed to assist institutions in the Africa region to implement and self-monitor the integration of social accountability into their optometry programmes (Moodley, Loughman, and Naidoo 2016).

On inspection, Mozambique's existing ophthalmic technicians (OTs) demonstrated inadequate refraction skills. Their confidence and competence in refraction varied depending on training, location of work, clinical load, availability of equipment and other eye care personnel. Upskilling was found to have a significant positive impact on OT confidence and competence levels in refraction (Shah et al. 2016).

Under the MEP, a comprehensive framework of competency standards for OTs and optometrists in Mozambique was developed using a modified Delphi consensus approach involving local and international experts. Once the optometry degree program was operational, studies were undertaken to inform the design of the competency assessment process (Shah et al. 2015; Shah et al. 2017). Only four students out of 15 optometry degree students were graded as clinically competent in refraction. Analyses indicated that student 
learning context, teaching context, clinic conditions and assessment, and the existing operating health care context were important determinants of student refraction competencies. This competency framework has informed the curricula for both cadres in relation to important aspects of training including communication, patient evaluation, patient management, community, technical, and research and training. In addition, it has improved the structure of teaching and learning environments by recommending a preparatory year, a review of the curriculum and clinic structure, more transparent entry requirements and better internet infrastructure (Shah et al. 2015). The framework has the potential for replication in other regions where there is a need to develop socially responsive education for eye health professionals (Shah, Naidoo, and Loughman 2016).

Limited access to education is a stark reality for many students in the Africa region. Barriers to optometric education in Mozambique included cost, lack of knowledge of optometry, high admission criteria, limited student spaces, poor mathematics and science results, gender inequalities and geographical challenges. A lack of funding was identified as the main contributing factor for high attrition rates from university where students had to pay their own fees. Where tertiary education was free, the limited number of spaces available was the major barrier to access (Moodley, Loughman, and Naidoo 2014). Low awareness of optometry as a profession was found to impact on student recruitment and expectations (Shah et al. 2015). Despite these findings, optometry students acknowledged a lack of eye health personnel in Mozambique and that optometry training would resolve this challenge. Understanding prospective student perceptions and expectations can assist the development of student support systems and awareness strategies for eye health professional training (Chan et al. 2015). Several other institutional and socio-economic factors also contributed to disparities in recruitment and selection. It was concluded that for optometric education programmes in Africa to have a meaningful impact, geographical, gender, economic and educational disparities must be addressed (Moodley, Loughman, and Naidoo 2015).

Inadequate HR to address RE is a key supply-side barrier to eye health services. A study of the perceptions of over 1,000 Mozambicans with VI indicated that cost was the most frequently cited demand-side barrier, as identified by $53 \%$ of participants. Other barriers included lack of felt need $(20 \%)$, distance to travel (15\%), and lack of awareness (13\%). These critical barriers to RE services in Mozambique must be considered to ensure service uptake by the general population and to inform decision-making for improved service delivery (Thompson et al. 2015).

The MEP experience provides useful lessons for the planning of future development programmes. The lessons will have particular resonance for those responsible for planning future sustainable eye health education and service delivery models for low income settings. Figure 1 summarises the MEP outputs and achievements against the objectives of the World Health Organization's Global Action Plan for Universal Eye Health (World Health Organization 2013). With a goal of achieving a measurable reduction of $25 \%$ of 
avoidable VI by 2019, the objectives focused on the generation of evidence through multi-sectoral partnerships to strengthen eye health systems.

[Figure 1]

\section{Conclusion}

The supply of adequately trained eye health professionals to meet the demand for refraction in Mozambique is currently insufficient (Moodley, Loughman, and Naidoo 2014). As with many countries in Africa, there is an urgent need for the development and delivery of a comprehensive RE service in Mozambique (Loughman et al. 2015). Sustainable international collaborative approaches to develop HR to address URE have been shown to be economically justifiable and should be considered in countries where HR are similarly deficient (Thompson et al. 2014)

Eye health projects (and development projects in general) must address issues of professional identity. Developing adequate health profession regulations is necessary, so that graduate qualifications are legitimised through official recognition by relevant local authorities (Wallace, Loughman, and Naidoo 2016).

To address barriers to optometric education (cost, lack of knowledge, high admission criteria, limited student spaces, poor results, gender inequalities and geographical challenges) educators, policymakers and health professionals must together formulate strategies to increase access (Moodley, Loughman, and Naidoo 2014). Student awareness of optometry can promote its development as a primary healthcare profession (Chan et al. 2015). For optometry education programmes in Africa to have a meaningful impact on meeting societal needs, universities must integrate social accountability in all facets of education, including curriculum design, research, recruitment and selection (Moodley, Loughman, and Naidoo 2015).

Socially responsive, competency-based approaches can enable coordinated training and development for all mid-level eye care personnel and optometrists in low income contexts (Shah, Naidoo, and Loughman 2016). Guidance on the selection of competency assessment methods would assist institutions to adopt models that can be sustained locally, giving due regard to limited available resources (Shah et al. 2017). Identifying factors affecting refraction competence, in collaboration with the academic faculty, can strengthen teaching and improve learning environments for optometric education (Shah et al. 2015). The upskilling of existing eye health workers in low income contexts can also effectively improve confidence and competence levels for refraction (Shah et al. 2016).

The development of HR for eye health alone is not sufficient to address the burden of avoidable $\mathrm{VI}-\mathrm{a}$ comprehensive approach must be taken to strengthen all aspects of eye health and the broader health system. To be effective, public sector refractive services must consider the demand-side implications of cost, 
affordability and geographical inequalities. They must also have a clear strategy for overcoming lack of felt need through improved advocacy and health promotion (Thompson et al. 2015).

\section{Disclosure statement}

No potential conflict of interest was reported by the authors.

\section{Funding}

This research was produced as part of the Mozambique Eyecare Project, which was funded by Irish Aid.

\section{References}

Chan V, Loughman J, Moodley V, Bilotto L, Naidoo K. 2015. Student Educational Background, Perceptions and Expectations towards Optometry: an Emerging Eye Health Profession Mozambique. Optometric Education;40(2): 104-109.

Loughman J, Nxele L, Faria C, Thompson S, Ramson P, Chinanayi F, Naidoo K. 2015. Rapid Assessment of Refractive Error, Presbyopia and Visual impairment and associated Quality of Life in Nampula, Mozambique. Journal of Visual Impairment \& Blindness; 109(3) 199-213

Moodley V, Loughman J, Naidoo K. 2014. Access to Optometric Education: Challenges in Sub-Saharan Africa. Literacy Information and Computer Education; 5(3): 1634-1640

Moodley V, Loughman J, Naidoo K. 2015. Recruitment and Selection Strategies in Optometric Education Towards Addressing Human Resource Disparities In Sub-Saharan Africa. Africa Education Review; 12(3): 429-446.

Moodley V, Loughman J, Naidoo K. 2016. Social Accountability: Introducing a new dimension in optometric education. South African Journal of Higher Education;30(1): 206-223

Shah K, Naidoo K, Bilotto L, Loughman J. 2015. Factors affecting the academic performance of optometry students in Mozambique. Optometry and Vision Science;92(6): 719-29.

Shah K, Naidoo K, Loughman J. Development of socially responsive competency frameworks for ophthalmic technicians and optometrists in Mozambique. Clinical and Experimental Optometry. 2016;99(2): 173-82.

Shah K, Naidoo K, Chagunda M, Loughman J. 2016. Evaluations of refraction competencies of ophthalmic technicians in Mozambique. Journal of Optometry;9(3): 148-157. 
Shah K, Naidoo K, Bilotto L, Loughman J. 2017. Competency-based Assessment of Refractive Error Measurement in a Mozambique Optometry School. Optometric Education; 42(2): 27-36.

Thompson S, Naidoo K, Gonzalez-Alvarez C, Harris G, Chinanayi F, Loughman J. 2015. Barriers to utilisation of refractive services in Mozambique. Optometry and Vision Science; 92(1): 59-69.

Thompson S, Naidoo K, Harris G, Ferrao J, Loughman J. 2014. The development of a public optometry system in Mozambique: a Cost Benefit Analysis. BMC Health Services Research;14(1): 422-430

Wallace D, Loughman J, Naidoo K. 2016. Framing professional programs within development projects: driving longer term recognition and integration. BMC Medical Education; 16(1): 116-126

World Health Organization. 2013. Universal eye health: a global action plan 2014-2019. World Health Organization. Geneva, Switzerland.

World Health Organization. 2017. Vision impairment and blindness Factsheet. World Health Organization. Geneva, Switzerland. 
Table 1 - Net Present Value of societal benefits (\$) for the first 10 years of the optometry programme.

\begin{tabular}{rr}
\hline Year & Net Present Value of societal benefits (\$) \\
\hline 2009 & $-273,596$ \\
2010 & $-529,534$ \\
2011 & $-630,384$ \\
2012 & $-595,349$ \\
2013 & $-308,291$ \\
2014 & $1,069,098$ \\
2015 & $3,641,100$ \\
2016 & $6,589,276$ \\
2017 & $9,558,510$ \\
2018 & $12,403,620$ \\
2019 & $15,002,333$ \\
\hline
\end{tabular}




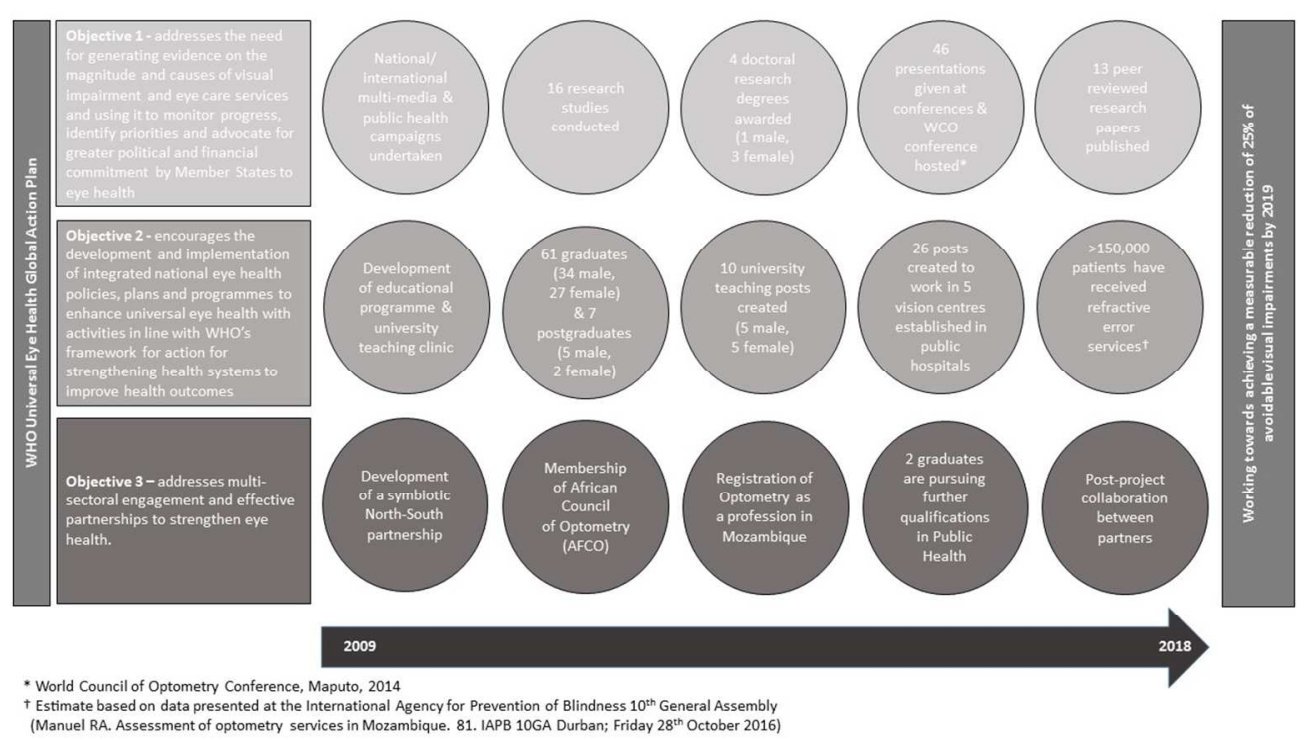

Figure 1 - Outputs and achievements of the MEP in relation to the Global Action Plan objectives $338 \times 190 \mathrm{~mm}(96 \times 96 \mathrm{DPI})$ 